\title{
Comparison of the two time schedules for endoscopic sclerotherapy: a prospective randomised controlled study
}

\author{
S K SARIN, G SACHDEV, R NANDA, S K BATRA, AND B S ANAND \\ From the Department of Gastroenterology, GB Pant Hospital, New Delhi, India
}

SUMmARY To compare the efficacy and safety of one week versus three weeks interval treatment schedules of endoscopic sclerotherapy, injections were carried out in a prospective manner in 96 patients with variceal bleeding; 47 on a one week and 49 on a three weeks treatment schedule. Weekly endoscopic sclerotherapy eradicated oesophageal varices significantly $(\mathrm{p}<0 \cdot 01)$ earlier (mean \pm SD $7 \cdot 1 \pm 2.43$ weeks) as compared with the three weeks regimen (mean \pm SD $14 \cdot 86 \pm 4 \cdot 86$ weeks). The rebleeding rate was also significantly less $(\mathrm{p}<0.05)$ with weekly endoscopic sclerotherapy $(8 \cdot 5 \%)$ as compared with three weeks endoscopic sclerotherapy treatment $(26 \cdot 5 \%)$. The amount of alcohol and the number of endoscopic sclerotherapy courses required for complete variceal eradication did not differ significantly between the two groups. Patients undergoing weekly injections were seen to have significantly more oesophageal ulcers $(\mathrm{p}<0 \cdot 01)$ as compared with the three weeks group, necessitating at times $(23 \%)$ postponement of the procedure. There was, however, no difference between the two groups in the frequency of oesophageal stricture formation, dysphagia, retrosternal pain, and fever. Mortality was also similar in the two groups. It can be concluded that a weekly schedule of endoscopic sclerotherapy appears superior to a three weeks schedule.

There is no universal agreement on the optimum interval necessary between two courses of endoscopic sclerotherapy. ${ }^{12}$ Schedules ranging from a three day to a six month interval are in vogue. ${ }^{2-8}$ Most investigators have held that endoscopic sclerotherapy done earlier than three weeks increases the complication rate with little added advantage. ${ }^{2+5}$ In an earlier study, we have reported that a weekly schedule of endoscopic sclerotherapy is quite safe and effective. ${ }^{2}$ The present communication compares the efficacy, safety, and utility of one week or three week interval endoscopic sclerotherapy treatment schedules, in patients with oesophageal variceal bleeding.

\section{Methods}

PATIENTS

Ninety six consecutive patients presenting with variceal bleeding between October 1983 to January 1985 were included in the study. In each of the

Address for correspondence: Dr S K Sarin. MD, DM. GB Pant Hospital, New Delhi, 110002 , India.

Received for publication 12 September 1985 patients, the diagnosis of bleeding oesophageal varices was confirmed by endoscopy. None of the patients had other causes such as peptic ulcer or erosive mucosal disease responsible for upper gastrointestinal bleeding. Portal hypertension was caused by alcoholic cirrhosis in 36 , posthepatitic or cryptogenic cirrhosis in 39 , non-cirrhotic portal fibrosis in 20, extrahepatic portal obstruction in nine and Budd-Chiari syndrome in two patients. Twenty six patients were in Child's A, 24 in Child's B, and 46 in Child's C category. ${ }^{9}$ All patients had a history of moderate upper gastrointestinal haemorrhage. ${ }^{11}$ Variceal size was graded from 1 to $4 .^{11}$ No patient was excluded from the trial because of massive bleeding or hepatic encephalopathy.

Patients were allocated either to weekly or three weekly sclerotherapy using a table of random numbers, immediately after admission. The nature of the treatment schedule was explained to each patient and strict adherence to the protocol was stressed.

The clinical features of the patients in the two treatment groups were analysed and were comparable (Table 1). 
Table 1 Clinical presentation of patients with variceal bleeding

\begin{tabular}{lll}
\hline Parameter & $\begin{array}{l}1 \text { week } \\
(n=47)\end{array}$ & $\begin{array}{l}3 \text { week } \\
(n=49)\end{array}$ \\
\hline $\begin{array}{l}\text { Mean ( } \pm \text { SD) age }(\mathrm{yr}) \\
\text { Male:femalc }\end{array}$ & $\begin{array}{l}31 \cdot 9 \pm 13 \cdot 4 \\
27: 20\end{array}$ & $\begin{array}{l}35 \cdot 2 \pm 16 \cdot 7 \\
28: 21\end{array}$ \\
$\begin{array}{l}\text { Aetiology } \\
\text { Cirrhosis }\end{array}$ & 34 & 31 \\
NCPF* & 8 & 12 \\
EHO+ & 5 & 4 \\
Budd-Chiari syndrome & - & 2 \\
Child's Grade & 12 & 14 \\
A & 9 & 15 \\
B & 26 & 20 \\
C & & \\
Variceal grade & 1 & 3 \\
2 & 15 & 22 \\
3 & 31 & 24 \\
4 &
\end{tabular}

* NCPF - Non-cirrhotic portal fibrosis, + EHO - Extra-hepatic obstruction.

\section{TECHNIQUE}

Endoscopic sclerotherapy was carried out using absolute alcohol as a sclerosant, an indigenously designed Teflon injector and a flexible fibreoptic endoscope (Olympus GIF Q, D3 or XP) as described in detail earlier. ${ }^{2}{ }^{12}$ Endoscopic sclerotherapy was done on an outpatient basis, unless the patient was already admitted to the hospital because of primary liver disease or upper gastrointestinal bleeding.

Injections were given intravariceally and were limited to the lower $6 \mathrm{~cm}$ of the oesophagus. Variceal columns extending higher up were not injected because they were seen to disappear gradually after the obliteration of the columns lower down. Blanching of the variceal wall around the injection site was considered desirable. Rebleeding was defined as any variceal bleeding occuring prior to the next course of endoscopic sclerotherapy. The diagnosis of bleeding from the varices was only considered if active bleeding was identified from a varix or if a clot was seen adherent to a varix and a thorough examination of the stomach and duodenum failed to reveal an alternative cause of bleeding.

Endoscopic sclerotherapy was repeated at regular weekly or three weekly intervals. Repeat injections were given at a distance of about $2 \mathrm{~cm}$ from the previous injection sites, avoiding ulcerated areas. Endoscopic sclerotherapy was, however, postponed, if at the time of subsequent injections diffuse mucosal ulcerations with slough were present over all the variceal columns. A repeat endoscopy in such cases was done after a gap of three weeks and the feasibility and necessity of repeat endoscopic sclerotherapy was assessed. Total eradication of the varices was considered as the end point of the trial (except where the patient died or was lost to follow up). Total variceal eradication was accepted only when no variceal column was visible all around the circumference of the lower 5-6 cm of the oesophagus. Presence of an occasional, single tiny remanent not more than 0.5 to $1.0 \mathrm{~cm}$, was considered insignificant and consistent with total variceal eradication. The efficacy of the two treatment schedules was then analysed by the following parameters; the number of endoscopic sclerotherapy sessions required, the time needed for eradication, the amount of sclerosant used, the number of rebleeding episodes, and the frequency of complications.

Statistical analysis was made using the Student's $t$ test and $\chi^{2}$ test with Yates' correction.

\section{Results}

Two hundred and fifty five and 197 sessions of endoscopic sclerotherapy were given to 47 and 49 patients on one week and three week schedules respectively (Table 2). Patients on the one week schedule required significantly $(\mathrm{p}<0 \cdot() 1)$ less time as compared with those receiving injections every

Table 2 Comparison of the efficacy of two treatment schedules*

\begin{tabular}{|c|c|c|c|}
\hline Parameter & $\begin{array}{l}\text { I week } \\
(n=47)\end{array}$ & $\begin{array}{l}3 \text { week } \\
(n=49)\end{array}$ & $P$ \\
\hline $\begin{array}{l}\text { Total endoscopic } \\
\text { sclerotherapy sessions }\end{array}$ & 255 & 197 & \\
\hline $\begin{array}{l}\text { Mean duration (wecks) for } \\
\text { variceal cradication }\end{array}$ & $7 \cdot 1 \pm 2 \cdot 43$ & $14 \cdot 8 \pm 4 \cdot 86$ & $<() \cdot() 1$ \\
\hline $\begin{array}{l}\text { Mean amount of alcohol } \\
(\mathrm{ml}) / \mathrm{pt}\end{array}$ & $28 \cdot 9 \pm 11 \cdot 4$ & $24 \cdot 6 \pm 43 \cdot 2$ & $\mathrm{NS}+$ \\
\hline $\begin{array}{l}\text { Mean number of injection } \\
\text { courses/pt }\end{array}$ & $5.79 \pm 1.71$ & $4 \cdot 8 \pm 1 \cdot 54$ & NS \\
\hline Complications & & & \\
\hline Ulcer & $68.7 \%$ & $12 \%$ & $<0 \cdot() 1$ \\
\hline Stricture & $8.5 \%$ & $6.1 \%$ & NS \\
\hline Dysphagia & $6(0.9 \%$ & $53 \cdot 0 \%$ & NS \\
\hline Rebleceding & $8.5 \%$ & $26.5 \%$ & $<(0 \cdot 05$ \\
\hline Fever & $32 \cdot(1 \%$ & $36.5 \%$ & NS \\
\hline Transicnt increase in ascites & $\leqslant 6.4 \%$ & $4.1 \%$ & NS \\
\hline Pncumonitis & - & $2 \cdot 6 \%$ & NS \\
\hline Death & $10 \cdot 6 \%$ & $6.1 \%$ & NS \\
\hline Dropout & $4.3 \%$ & $14 \cdot 3 \%$ & NS \\
\hline
\end{tabular}

* Values of different parameters are mean \pm SD.

+ NS denotes not significant.

$¥$ Median number of injection courses required by weekly endoscopic sclerotherapy group was six (range 3-10) and three weekly group, was five (range 3-11). 
three weeks for total variceal eradication (Figure). The total amount of alcohol required and the total number of endoscopic sclerotherapy sessions needed by the two groups of patients for variceal eradication were similar.

In all, 27 episodes of bleeding occurred in 17 patients; 10 had one rebleed, another four had two and three patients had a total of three rebleeds. Thirteen of the patients who rebled were undergoing weekly injections. The difference was significant $(p<0.05)($ Table 2$)$. In $64 \%$ of the patients rebleeding occurred after the first, in $27 \%$ after the second and in the remaining after the third course of endoscopic sclerotherapy. Rebleeding was not seen in any of the groups after four courses of endoscopic sclerotherapy. All the rebleeding episodes in patients on weekly schedule occurred during their stay in the hospital as compared with the other group, where $45 \%$ of the episodes occurred after the patients were discharged from hospital. Size of the varices or the severity of the liver disease did not significantly influence the rebleeding episode. Of the 17 patients who rebled; 10 had grade four and seven had grade three varices. Nine $(53 \%)$ patients who rebled, had Child's $C$, three ( $18 \%$ ) had Child's B, while five (29\%) patients had Child's A grade of liver disease.

Ulcerations over the oesophageal varices were detected in $69 \%$ of the patients who were on weekly schedule and $12 \%$ of those on three weekly regimen. The differences was significant $(p<0 \cdot 01)$. Because of diffuse ulcerations present over the lower portions of all the variceal columns, endoscopic sclerotherapy had to be postponed on 26 occasions in $11(23 \%)$ patients, all undergoing weekly injections. Mucosal ulcerations were generally seen during the initial two to three

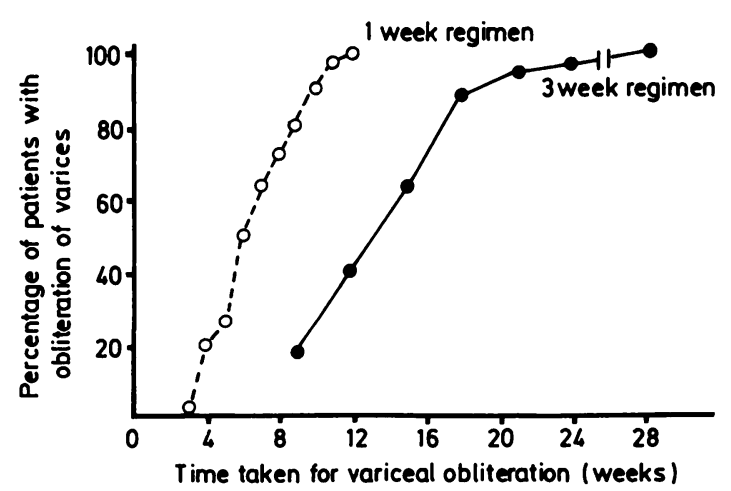

Figure Shows a comparison of the one week and three week sclerotherapy schedules in achieving total variceal obliteration. endoscopic sclerotherapy courses. In three of these patients varices were seen to get obliterated totally on repeat endoscopies without further courses of sclerotherapy. None of the patients in the three week group showed diffuse mucosal ulcerations necessitating postponement of endoscopic sclerotherapy.

The incidence and extent of mucosal ulcerations did not have any significant bearing on the frequency of retrosternal pain, dysphagia or stricture formation. Retrosternal pain and dysphagia were short lasting and their frequency was similar in the two treatment groups. Fever after endoscopic sclerotherapy was also transient in nature, subsiding within 24-72 hours in almost all patients. Four patients $(8.5 \%)$ in the weekly group and three $(6 \%)$ in the three week group developed oesophageal stricture. Except for one patient in the three week group, all patients with an oesophageal stricture improved on repeated medical (Eder-Puestow) dilatations.

There were eight deaths; five in the one week and three in the three week treatment group respectively. Three of five deaths in the former groups were because of progressive hepatocellular failure and encephalopathy. One patient with pulmonary tuberculosis developed fatal hydropneumothorax after endoscopic sclerotherapy and died. The other patient succumbed to uncontrolled bleeding during the first course of endoscopic sclerotherapy. In the three week group, two of the three deaths were caused by rebleeding and one was due to hepatic encephalopathy. Seven patients dropped out from the three week schedule compared with only two from the one week schedule. The difference was not significant. Seven of the total nine dropouts were Child's C. The possibility of some of them having died cannot be ruled out.

\section{Discussion}

Endoscopic sclerotherapy done on a weekly basis eradicated oesophageal varices significantly $(p<0 \cdot 01)$ earlier than a three weekly schedule. This was achieved with no increased incidence of complications. Oesophageal ulcerations were, however, detected significantly $(p<0 \cdot 01)$ more often in the weekly treated group $(69 \%$ vs $12 \%)$. The high incidence of oesophageal ulceration with the weekly injections is probably because of earlier endoscopic examination. ${ }^{2}$ It is possible that many of these ulcers heal by three weeks, giving a low incidence of ulcerations in the three week injection group.

The incidence of rebleeding was significantly lower in the one week endoscopic sclerotherapy group $(8.5 \%)$ than the three week group $(26 \cdot 5 \%)$. 
The difference in the rebleeding rates between the two groups could possibly be because of a delay in variceal obliteration in the three weekly injection group. This is supported by the fact that the incidence of rebleeding diminished as more and more endoscopic sclerotherapy courses were carried out. Sixty four per cent of patients rebled after the first course of endoscopic sclerotherapy, $27 \%$ after the second and the remaining $9 \%$ after the third course. It therefore, appears that the earlier one can accomplish four or more successful endoscopic sclerotherapy courses; the less would be the chances of rebleeding from the varices. It is well known that the majority of the rebleeding episodes occur within two weeks of the index bleed and the risk of rebleeding or death rapidly diminishes over the first few days after a bleed and early survival may be the best marker for late survival. ${ }^{13,}{ }^{14}$ Although, by giving weekly endoscopic sclerotherapy, we observed significant reduction in rebleeding rate, it is not possible to say on the basis of our results, whether this reduction decreases the incidence of hepatic encephalopathy and improves the overall survival in patients with variceal bleeding. In the only other study by Westaby et al comparing the efficacy of one and three weeks treatment schedules, 11 of the 28 patients in the one week group and 14 of 27 patients in the three week group rebled. ${ }^{4}$ The difference between the two groups was not significant; possibly because of the small number of patients.

Endoscopic sclerotherapy was postponed in $23 \%$ of the patients undergoing weekly endoscopic sclerotherapy, because of mucosal ulcerations at endoscopy. Westably et al have also reported the presence of extensive mucosal ulcerations necessitating postponement of endoscopic sclerotherapy in $68 \%$ of patients undergoing weekly injections. ${ }^{4}$ Like them, we have observed that postponement of the endoscopic sclerotherapy for three weeks in these patients led to healing of the mucosal ulcers making the next endoscopic sclerotherapy course possible. We however, found that in some of the patients (three of 11), with diffuse mucosal ulcerations, varices gradually disappeared with healing of ulcers without further injections. What should then be the optimal interval between two courses of endoscopic sclerotherapy? Although, the weekly schedule of endoscopic sclerotherapy cannot be considered absolutely ideal, it was found to be significantly superior to the three weeks regimen as it achieved variceal eradication earlier and was accompanied by a reduced rebleeding rate. The higher incidence of oesophageal ulcerations seen in these patients has been found to be inconsequential ${ }^{15}$ and the occasional postponement of endoscopic sclerotherapy due to mucosal ulcerations, a small price to pay. While we recommend a weekly schedule of sclerotherapy, further studies are suggested to find out the optimal interval between the two sclerotherapy courses.

\section{References}

1 Conn HO. Endoscopic sclerotherapy: An analysis of variants. Hepatology 1983; 3: 769-71.

2 Sarin SK. Sachdeva G, Nanda R, Vij JC, Anand BS. Endoscopic sclerotherapy using absolute alcohol. Gut 1985; 26: 120-4.

3 Cello JP, Grandell JH, Crass RA, Trunkey DD, Cobb EE, Heilbron DC. Endoscopic sclerotherapy versus portacaval shunt in patients with severe cirrhosis and variceal haemorrhage. $N$ Engl $J$ Med 1984; 311: 1589-94.

4 Westaby D, Melia WB, MacDougall BRD. Hegarty $\mathrm{JE}$, Williams R. Injection sclerotherapy for oesophageal varices: A prospective randomized trial of different treatment schedules. Gut 1984; 25: 129-32.

5 Clark AW, MacDougall BRD, Westaby D, et al. Prospective controlled trial of injection sclerotherapy in patients with cirrhosis and recent variceal haemorrhage. Lancet 1980; 2: 552-4.

6 Terblanche J, Bornman PC, Khan D, et al. Failure of repeated injection sclerotherapy to improve long-term survival after oesophageal varices bleeding. Lancet 1983; 2: 1328-32.

7 Annonymous. Bleeding oesophageal varices. [Editorial]. Lancet 1984; 1: 139-4.

8 Heig WE, Stange EF, Ruetteanaure K, Ditschuneit H. Emergency endoscopic sclerotherapy for bleeding oesophageal varices: a prospective study in patients not responding to balloon tamponade. Gastrointest Endosc 1983; 29: 8-14.

9 Child CG, Turcottee JG. Surgery in portal hypertension. In: Child CG, ed. Major problems in clinical surgery: the liver and portal hypertension. Philadelphia: Saunders, 1964: 1-85.

10 Pickard RG, Sanderson I, South M, Kirkham JS, Northfield TC. Controlled trial of cimetidine in acute upper gastrointestinal bleeding. $\mathrm{Br}$ Med J 1979; 1: 661-2.

11 Conn HO. Ammonia tolerance in the diagnosis of oesophageal varices. A comparison of endoscopic, radiologic and biochemical techniques. J Lab Clin Med 1967; 70: 442-51.

12 Sarin SK, Nanda R, Kumar N, Vij JC, Anand BS. Repeated endoscopic sclerotherapy for active variceal bleeding. Ann Surg 1985; 202: 708-11.

13 Smith JL, Grahm DY. Variceal hemorrhage. A critical evaluation of survival analysis. Gastroenterology 1982; 82: $968-73$.

14 Rose JDR, Crane MD, Smith PM. Factors affecting successful endoscopic sclerotherapy for oesophageal varices. Gut 1983; 24: 946-9.

15 Sarin SK, Nanda R, Vij JC, Anand BS. Oesophageal ulceration after endoscopic sclerotherapy - a complication or an accompaniment? Endoscopy (In press). 